\title{
Advancing Scholarship, Team Building, And Collaboration In A Hybrid Doctoral Program In Educational Leadership
}

Barbara Holmes, Hampton University, USA

Meridee Trimble, Hampton University, USA

Dietrich Morrison-Danner, Hampton University, USA

\begin{abstract}
Hybrid programs are changing the landscape of doctoral programs at American universities and colleges. The increased demand for hybrid doctoral programs, particularly for educational and career advancement, serves as an innovative way to increase scholarship, advance service, and promote leadership. Hybrid programs serve as excellent venues for advancing scholarship, collaboration, and team building and provide doctoral candidates with increased opportunities to engage professional peers, course material, and program resources. These opportunities lead to greater team engagement and enhanced opportunities for scholarly collaboration. Faculty mentors in hybrid programs lead rising scholars in the research and socialization process of higher education academic and social networks.
\end{abstract}

Keywords: Advancing Scholarship; Collaboration; Doctoral; Hybrid; Team Building

\section{INTRODUCTION}

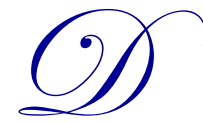

octoral programs face challenges to put the enabling conditions in place to assure that all learners persist through to program completion. Traditional doctoral programs have high attrition rates, ranging from $40 \%$ to $60 \%$, and online and hybrid doctoral students experience a $10 \%$ higher attrition rate (Ali \& Kohun, 2007; Alvich, Manning, McCormick, \& Campbell, 2012; Batts, Cry, Washington, \& Wickham, 2013; Spaulding \& Rockingson-Szapkiw, 2012). Common themes of attrition are evident in traditional, online, and hybrid programs; however, the challenges of hybrid programs, particularly because of the physical disconnect from faculty and fellow students, compound the phenomenon of high attrition in doctoral programs (Bain, Fedynich, \& Knight, 2009). Batts, Cry, Washington, and Wickham (2013) cite that inadequate communication with cohort members, and the inaccessibility of, and communication with dissertation committee members are contributing factors to attrition.

In spite of high attrition rates, doctoral programs aim to create active academic scholars and contributors to the field. Justus (2011) concludes that the learning environment in hybrid doctoral programs is inherently different than are traditional programs, which necessitates a focus on advancing scholarship, team building, and collaboration, to ensure cohesive cohorts and productive students.

On the other hand, hybrid doctoral programs are especially challenging and have higher attrition as compared to traditional face-to-face programs. Boes et al. (1999) suggest that before students are even reviewed for selection, they should be made aware of the challenges and demands of doctoral study through material distributed about the program. Then, potential students can make informed choices whether they can adequately balance the demands of professional career, family, and other responsibilities. Programs should encourage potential applicants to research and study the demands and rigor of pursuing the highest academic degree. In other words, due diligence on doctoral student attrition should be encouraged before students are admitted into programs. This is one way to get students started on implementing research to answer current issues and problems.

Hybrid doctoral programs in educational leadership remain attractive to educational practitioners because 
of the freedom to pursue professional careers, maintain families and community ties and, at the same time, work on an advanced degree. For this reason, hybrid programs serve as an innovative means to "potentially increase the pool of leaders" (Alvich, Manning, McCormick, \& Campbell, 2012, p. 231) by providing an academic outlet for doctoral students to link professional experiences to educational theory. However, this is unfamiliar territory and many doctoral students do not know how to master the terrain. They enter doctoral programs with the same skill sets that were useful at the master's level and cannot or do not make the appropriate adjustments to the rigors of doctoral study in a timely manner.

Overcoming barriers associated with increasing doctoral student persistence rates remains an institutional priority. Hybrid programs represent an excellent venue for building collaboration and team building. Kearsley (2000) asserts that learning in a virtual environment is as much a social activity as it is a learning activity. However, students must learn how to collaborate and be provided with opportunities for that collaboration to foster. Particular attention paid to keeping the learner engaged with the course content, as well as engaged with co-learners, is necessary. The goal is to build a team of academic professionals who can collaborate and work together in a way not bound by time, place, and space.

\section{INSTITUTIONAL CONTEXT}

Hampton University was founded in 1868 and is a Historically Black College and University (HBCU) located in Hampton, Virginia, offering technical, engineering, science, business, journalism, nursing, pharmacy, and liberal arts degrees at the bachelor's, master's, doctoral, and professional levels (Hampton University, 2014b). Alvich, Manning, McCormick, and Campbell (2012) cited a supply gap in institutions providing hybrid doctoral programs to accommodate the needs of working professionals. Responding to the demand, Hampton University was a pioneer among HBCUs, in January 2011, to establish a hybrid educational management Ph.D. program. Situated within Hampton University's School of Education and Human Development, the 66-credit program offers two specialization tracks: K-12 and higher education. The educational management doctoral student population, grouped into cohorts, is primarily comprised of middle and executive-level professionals who desire to maintain a full-time career while pursuing a research-based doctorate degree.

The educational management program is delivered in an executive format to fully employed educational practitioners. The program's hybrid delivery format provides a balance of virtual and in-residence education. Because this program leads to a research-based degree, course projects, assignments, field experiences, and dissertations focus on the most pressing educational challenges faced by PK-12 and higher education organizations.

The virtual component operates via Blackboard, where students asynchronously take six credits of coursework per nine-week semester for five semesters per academic year. Additionally, advising sessions via GoToMeeting provide virtual face-to-face mentoring and guidance. The residency component takes place during two summers at the Hampton University campus. Doctoral cohorts attend two-week residencies to conduct research, collaborate with faculty and cohort members, and to observe proposal and dissertation defenses.

\section{METHODOLOGY}

This study investigated the perceptions of enrolled doctoral students on the development of academic scholarship and researcher self-efficacy. To achieve this purpose, a focus group methodology was employed. Sagoe (2012) affirms that focus groups are particularly effective in obtaining participants' feelings and opinions about a particular topic.

This study evolved from focus group discussions of doctoral cohort members over three academic semesters. Because of the collaborative nature of the cohort, members generously shared their perspectives on advancing scholarship, team building, and collaboration in virtual conference calls, GoToMeeting sessions, projectbased learning activities, and during residency. During these four focus group sessions, the purpose was to explore doctoral students' assessment of their evolving researcher self-efficacy and development as collaborative academic scholars. The focus groups encouraged participants to discuss perceptions of their matriculation through the doctoral program and to identify those areas and activities that were pivotal to individual growth and development as 
academic scholars. All of the focus group participants had been enrolled for a full academic year in the doctoral program and had completed a summer residency on campus. Focus group conversations facilitated the open sharing of information and dialogue among cohort members.

\section{ADVANCING SCHOLARSHIP}

Advancing scholarship in a hybrid doctoral program may be successfully accomplished through a variety of course-related activities, facilitated by the professor and students, and enabled by a university's investment in an advanced technological infrastructure. Hampton University's use of Blackboard, as a collaborative education tool, provides students the opportunity to interface with the professor and cohort members (Batts et al., 2013). Additionally, the GoToMeeting platform has facilitated meetings with program advisors and a dissertation workshop. Students' participation in discussion boards, posting work for visibility, collaborating, and giving and receiving constructive feedback advances scholarship and provides exposure to classmates' research and resources. Advancing scholarship through Blackboard enables students to learn from fellow cohort members about current issues and challenges in the educational environment. The exchange of experiences and ideas among cohort members working in PK-12 schools and universities offers critical exposure to topics in the field and builds students' capacity as educational leaders.

The advancement of scholarship may also occur through the opportunity to write and publish scholarly articles, or to present papers at educational leadership conferences, under the advisement of a professor serving as a research advisor. This concept was exemplified by Hampton University's Educational Management Ph.D. program Cohort I members at the 2013 National Black Graduate Student Conference, by Cohort V members at the 2014 International Academic Conference in Orlando, Florida, and at the 6th Annual Conference on Higher Education Pedagogy at Virginia Tech University (Batts et al., 2013; Hampton University, 2014). Research endeavors produced by hybrid doctoral students possessing a broad range of professional and leadership experiences narrow the delta between theory and practice (Koehler et al., 2013). For this reason, opportunities to advance scholarship are critical to doctoral students' academic and professional development. Faculty mentors lead rising scholars in the research and socialization process of higher education academic and social networks. Teaching students how to approach call for paper announcements, to write for a peer-reviewed journal, and to communicate research findings to an academic audience is a critical scholarly skill.

Linking Hampton University professors' practice of mentoring doctoral students to the extant literature, Bain, Fedynich, and Knight (2009) posit that a nurturing academic environment, with a particular focus on the relationship between faculty and students, and students' satisfaction with the program fosters persistence in doctoral program. Spaulding and Rockingson-Szapkiw (2012) cite Tinto's student integration theory, particularly academic and social integration, as an environmental factor that may bolster students' persistence. Additionally, the effort of Hampton University's faculty to advance scholarship, to increase doctoral completion success rates, and to prepare students for careers addresses the gap in faculty mentorship of minorities and students of color (Turner et al., 2012). Students' involvement in the aforementioned publishing and presentation opportunities may promote motivation and persistence, contributing to a diminished likelihood of attrition (Bain, Fedynich, \& Knight, 2009). Advancing scholarship in the Hampton University educational management doctoral program, through publishing and presentation opportunities, may broaden students' exposure to, and confidence in, scholarly research and writing under the supervision of a professor.

Ali and Kumar (2007) designed a framework to address the four stages of the doctoral process during which social isolation may affect students, specifically pre-admission, year one, year two through candidacy, and dissertation. The objective of Ali and Kumar's (2007) research was to determine what causes social isolation and how doctoral programs can reduce the phenomenon. The implementation of a cohort approach to doctoral programs and to incorporate collaborative activities into the curriculum emerged as themes from the research (Ali \& Kumar, 2007). Holmes, Robinson, and Seay (2010) advanced the body of literature about collaborative cohort learning with ten principles communicated to Hampton University cohorts during residency and during web-based mentoring and advising sessions. 


\section{TEAM BUILDING AND COLLABORATION}

Team building was cited an imperative to doctoral student persistence for the cohesion of Hampton University's Cohort I members, particularly because is it a hybrid program (Batts et al., 2013). Actualizing the team building concept occurred in three courses of Cohort V's curriculum: EDUO 611, Techniques in Educational Research; EDUO 710, Leadership, Theory, and Practice; and EDUO 711, Dynamics of Managing Organizational Performance. The opportunity to collaborate with cohort members and accomplish a group project operationalized the leadership theories and styles of the course, including the demonstration of task and relationship-focused behaviors (Guthrie \& Schuermann, 2010).

It was during team building and collaborative exercises that Cohort $\mathrm{V}$ members' strengths became evident, from technological expertise to organizational, editing, writing, and researching skills, to the display of personalities with motivating and uplifting characteristics. Each cohort member brought a different and valuable skill set to the task, providing for a practical division of labor. Cohort $\mathrm{V}$ members increasingly exhibited the five characteristics of collaborative teams in a hybrid environment: a definable membership, awareness of one's membership, a shared sense of purpose, member interaction, and the ability to act individually, as well as a unit of individuals (Johnson, Suriya, Yoon, Berrett, \& LaFleur, 2002).

The process of team building involved communicating, coordinating duties and feedback, and successfully completing a group project which served to foster cooperation, trust, cohesion, and minimized the feelings of social isolation. Because social isolation is cited as a factor contributing to doctoral student attrition (Ali \& Kohun, 2007; Bain et al., 2009; Holmes et al., 2010), courses with group projects served useful in reducing isolation as it provided a platform from which students could connect with one another. Although social isolation constitutes a problem in the retention of doctoral students, a positive implication of the attrition phenomenon is that the body of literature is expanding about doctoral persistence, creating awareness for graduate school administrators and current and potential students of hybrid doctoral programs. Attrition has negative consequences on the student and the university; therefore, a variety of frameworks have been developed and socialized throughout the doctoral process to heighten awareness about students' vulnerability to isolated feelings (Ali \& Kumar, 2007; Holmes et al., 2010; Willis \& Carmichael, 2011)

\section{CONCLUSION}

The learning environment in hybrid doctoral programs is inherently different than traditional programs, which necessitates a focus on advancing scholarship, team building, and collaboration to ensure cohesive cohorts and productive students. The expanding body of literature about persistence in hybrid doctoral programs serves as a timely and useful resource for faculty's use in designing programs toward these objectives. Additionally, the literature serves to inform and prepare students to contribute to the cohort's collective knowledge and to complete a doctoral program successfully.

\section{AUTHOR INFORMATION}

Dr. Barbara Holmes is Associate Professor and Program Coordinator of the Hampton University School of Education and Human Development Ph.D. Program in Educational Management.

Email: barbara.holmes@hamptonu.edu.

Meridee Trimble is a doctoral student in the Hampton University Ph.D. program in Educational Management with research interests that include cultural education, foreign language studies, and study abroad.

Email: merideetrimble@hotmail.com.

Dr. Dietrich Morrison-Danner is a graduate of the Hampton University Ph.D. Program in Educational Management and currently serves Durham Public Schools, Durham, N.C. as Professional Development Coordinator. Email: damdanner@gmail.com. 


\section{REFERENCES}

1. Ali, A. \& Kohun, F. (2007). Dealing with social isolation to minimize doctoral attrition: A four stage framework. International Journal of Doctoral Studies, 2, 33-49.

2. Alvich, D., Manning, J., McCormick, K., \& Campbell, R. (2012). Hybrid doctoral program: Innovative strategies and partnerships. International Journal on E-Learning, 11(3), 223-232.

3. Bain, S., Fedynich, L., \& Knight, M. (2009, October). The successful graduate student: A review of the factors for success. Journal of Academic and Business Ethics, 3, 1-9.

4. Batts, B., Cry, T., Washington, R., \& Wickham, J. (2013). Exploring virtual destinies: Online doctoral students in educational leadership creating new paths to the future. Paper presented to the 2013 National Black Graduate Student Conference, Dearborn, MI.

5. Boes, S. R., Ullery, E. K., Millner, V. S., \& Cobia, D. C. (1999). Meeting the challenges of completing a counseling doctoral program. Journal of Humanistic Education and Development, 3, 130-144.

6. Guthrie J. W. \& Schuermann, P. J. (2010). Successful school leadership-- planning, politics, performance, and power. Boston, MA: Allyn \& Bacon.

7. Hampton University. (2014a). Best paper nominees from the international academic conference. Retrieved from http://gradcoll.hamptonu.edu/media/docs/20140123_155958_Educational\%20Management \%20Success\%20News\%20January\% 202014\%20pdf\%20version.pdf.

8. Hampton University. (2014b). Facts and figures. Retrieved from http://www.hamptonu.edu/about/facts.cfm.

9. Holmes, B. D., Robinson, L., \& Seay, A. D. (2010, July). Getting to finished: Strategies to ensure completion of the doctoral dissertation. Contemporary Issues in Education Research, 3(7), 1-8.

10. Johnson, S. D., Suriya, C., Yoon, S. W., Berrett, J. V.,\& LaFleur, J. (2002). Team development and group processes of virtual learning teams. Computers and Education, 39, 379-393.

11. Justus, M. (2011, October 18). Transformative virtual learning teams in doctoral education: The role of interdependence. In Proceedings of World Conference on E-Learning in Corporate, Government, Healthcare, and Higher Education 2011 (pp. 1351-1354). Chesapeake, VA: AACE.

12. Koehler, M. J., Zellner, A. L., Roseth, C. J., Dickson, R., K., Dickson, W., P., \& Bell, J. (2013, May/June). Rethinking the doctorate: Introducing the first hybrid doctoral program in educational technology. TechTrends, 57(3), 47-53.

13. Kumar, S. \& Dawson, K. (2012, March). Theory to practice: Implementation and initial impact of an online doctoral program. Online Journal of Distance Learning Administration, 15(1).

14. Segoe, D. (2012). Precincts and prospects in the use of focus groups in social and behavioral science research. The Qualitative Report, 17(29), 1-16. Retrieved from http://www.nova.edu/ssss/QR/QR17/sagoe.pdf.

15. Spaulding, L. S. \& Rockingson-Szapkiw, A. J. (2012). Hearing their voices: Factors doctoral candidates attribute to their persistence. International Journal of Doctoral Studies, 7, 199-219.

16. Turner, C. S. V., Wood, J. L., Montoya, Y. J., Essein-Wood, I. R., Neal, R., Escontrias, G., \& Coe, A. (2012). Advancing the next generation of higher education scholars: An examination of one doctoral classroom. International Journal of Teaching and Learning in Higher Education, 24(1), 103-112.

17. Willis, B. \& Carmichael K. D. (2011). The lived experience of late-stage doctoral student attrition in counselor education. The Qualitative Report, 16(1), 192-207. Retrieved from http://www.nova.edu/ssss/QR/QR16-1/willis.pdf. 
NOTES 